\title{
Growth of Silver Nanoparticles Using Polythiocyanatohydroquinone in Aqueous Solution
}

\author{
Valentina A. Litvin, ${ }^{1,}{ }^{\star}$ Boris F. Minaev, ${ }^{1,2}$ Rostislav L. Galagan, ${ }^{1}$ \\ Glib V. Baryshnikov ${ }^{1,2}$ and Hans Ågren ${ }^{2}$ \\ ${ }^{1}$ Department of Chemistry, Bohdan Khmelnitsky National University, Cherkassy, 18031, Ukraine \\ ${ }^{2}$ Division of Theoretical Chemistry and Biology, School of Biotechnology, KTH Royal Institute of Technology, \\ Stockholm, 10691, Sweden. \\ *Corresponding author: E-mail: litvin_valentina@ukr.net
}

Received: $12-01-2018$

\begin{abstract}
Motivated by evidence that silver nanoparticles have found numerous technological applications we have explored in this work utilization of polythiocyanatohydroquinone as a new efficient reducing and stabilizing agent for the preparation of such nanoparticles. The formation of silver nanoparticles has been confirmed by the UV-Vis spectroscopy, X-ray powder diffraction and by transmission electron microscopy. The potentiometric and spectroscopy kinetic measurements during the nanoparticles growth are also presented. Thermodynamic activation parameters for the silver nanoparticle formation have been determined from the reaction kinetic studies at variable temperatures. On the ground of observations using these techniques, a mechanism for silver nanoparticle growth has been proposed. The narrow size $(20-40 \mathrm{~nm})$ and spherical shape distribution of the fabricated nanoparticles together with the high stability of colloids for sedimentation provide a firm basis for applications of the polythiocyanatohydroquinone polymer as a reducing and stabilizing material for the metal nanoparticles preparation and storage.
\end{abstract}

Keywords: Silver nanoparticles; polythiocyanatohydroquinone; potentiometric study; spectrophotometric study; kinetics

\section{Introduction}

Silver nanoparticles (AgNPs) are of special interest because of their unique physicochemical properties, including optical, magnetic and electronic characteristics, catalytic activity and biological impact, ${ }^{1-3}$ which make these particles applicable in a variety of technological areas in medicine, agriculture, environment, and industry., The AgNPs have also a high potential as commercial nanomaterials in cosmetics and as effective antimicrobial agents. ${ }^{1,6}$

There are several methods proposed for fabrication of AgNPs, including chemical and physical approaches. ${ }^{7-9}$ Among them, the chemical reduction of silver ions in the presence of a protecting agent, is the most common and useful approach. Special attention is often devoted to the choice of reducing and capping agents since the physicochemical properties of the AgNPs are strongly dependent on the incorporated capping agent species. ${ }^{10-12}$ Organic polymers are in this context of especial interest because they can perform a reduction function while simultane- ously being adsorbed on the nanoparticles surfaces thereby stabilizing them. ${ }^{13-16}$

In this report we present the first attempt to synthesize AgNPs by using polythiocyanatohydroquinone (PTHQ) ${ }^{17}$ as a reducing and stabilizing agent with the aim to form the small size and highly distributed AgNPs. We present here kinetic investigations in order to predict the mechanism of the $\mathrm{Ag}^{+}$-ions reduction by PTHQ.

\section{Experimental}

\section{1. Materials}

All reagents (analytical-grade) were used as received from Sigma-Aldrich. De-ionized water $(18 \mathrm{M} \Omega / \mathrm{cm})$ from a Millipore Milli-Q water purification system was used to prepare all aqueous solutions. The synthesis of PTHQ has been described previously. ${ }^{17}$ Briefly, the PTHQ was synthesized by the three-stage synthesis. The 1,4-benzoquinone crystal was dissolved in the glacial acetic acid (GAA) and treated with the $\mathrm{NH}_{4} \mathrm{SCN}$ salt in the GGA medium. 
The forming benzene-1,4-diol and thiocyanogen at the same conditions produce next the ortho-substituted 2-thiocyanatobenzene-1,4-diol which polymerizes rapidly into the target PTHQ compound. The orange-brown PTHQ polymer was precipitated by water, filtered, washed and dried upon $80^{\circ} \mathrm{C}$.

\section{1. Preparation of silver nanoparticles using PTHQ}

In a typical experiment, a $19.6 \mathrm{mg}$ of PTHQ was disolved in $1.1 \mathrm{ml} 1 \mathrm{M}$ solution of $\mathrm{NaOH}$ and the volume was adjusted to $60 \mathrm{~mL}$ with distilled water. The flask with resulting mixed solution was placed in a thermostat water bath at $30^{\circ} \mathrm{C}$. Next, $3.0 \mathrm{~mL} 0.2 \mathrm{M} \mathrm{AgNO}_{3}$ was added under vigorous stirring. The final concentrations in the mixture were $1.67 \mathrm{mM}$ PTHQ, $18.3 \mathrm{mM} \mathrm{NaOH}$, and $10 \mathrm{mM}$ $\mathrm{AgNO}_{3}$.

Characterization. UV-Visible spectra were recorded as a function of reaction time on Lambda 35 Perkin Elmer UV-Visible spectrophotometer in the range of $320-520$ $\mathrm{nm}$. Aliquots of silver colloid $(0.2 \mathrm{~mL})$ were diluted to 25 $\mathrm{ml}$ for the UV-Visible experiments. The X-ray powder diffraction (XRD) analyses were performed on a DRON-2 $\mathrm{X}$-ray diffractometer (LOMO, Russia) with $\mathrm{Fe} \mathrm{Ka}$ radiation $(\lambda=1.9360 \AA)$ at a scanning speed of $0.01 \%$ s over the $2 \theta$ range of $20-120^{\circ}$. Transmission electron microscopy (TEM) was carried out by using a JEOL microscope (JEM$200 \mathrm{~A}$, Japan) with the accelerating voltage $200 \mathrm{kV}$. Samples for TEM investigations were prepared by evaporation of products on the surface of carbon films. The TEM images were registered with the $\mathrm{CE}$ video camera. The size of the particle can be calculated by using the scale provided in the micrograph. Potentiometric study the process of AgNPs formation was carried out on ionomer EV-74 with electrode system containing a glass electrode of type ESL63-07 and a silver electrode of type EVL-1M3. As a reference electrode was used silver-oxide half-cell. The FT-IR spectra of the samples were recorded on Perkin-Elmer spectrometer (SpectrumGX) with a resolution of $2 \mathrm{~cm}^{-1}$ over a scan range $4000-500 \mathrm{~cm}^{-1}$ using $\mathrm{KBr}$ pellet method.

Computational details. The structure of PTHQ active site in different oxidized forms has been optimized as oligomer at the density functional theory (DFT) level using the B3LYP ${ }^{18,19}$ hybrid functional and the $6-31 G(d)^{20}$ basis set. The edge vacancies within $-(\mathrm{C}=\mathrm{N})$ - chain of the PTHQ polymer have been terminated by methyl groups in the oligomer model. We have also calculated the IR spectra for the studied species. All vibration frequencies were found to be real, which indicates the global minimum finding on the potential energy hypersurface. For the correct estimation of ionization potential (IP) values the polarizable continuum model $(\mathrm{PCM})^{21}$ with water as a solvent has been used in the optimization procedure. The final IP values have been evaluated using Koopmans approach as the energy of the highest occupied molecular orbital (HOMO) with the opposite sign (IP $=-\varepsilon(\mathrm{HO}$ $\mathrm{MO})$ ). All the calculations have been carried out using the Gaussian- 16 program package. ${ }^{22}$

\section{Results and Discussion}

Stable aqueous colloids of AgNPs were prepared by chemical reduction of $\mathrm{Ag}^{+}$ions using the PTHQ in the presence of $\mathrm{NaOH}$. Due to the presences of phenolic group in the PTHQ structure ${ }^{17}$ the former reduces the $\mathrm{Ag}^{+}$ions to $\mathrm{Ag}^{0}$ atoms and are then adsorbed on the surface of the growing AgNPs. In the alkaline medium the chemosorbed PTHQ species and their partially oxidized products possess a large negative charge due to ionization of the hydroxyl and carboxyl groups. The repulsive forces prevent the aggregation of nanoparticles and provide stability of the colloidal system. The final colloids are stable and can be stored more the one year without aggregation.

$\mathrm{X}$-ray diffraction (XRD) results. The formation of the nanocrystalline AgNPs has been confirmed by the XRD analysis (Figure 1). Strong peaks observed at $48.6^{\circ}$, $56.8^{\circ}, 84.5^{\circ}, 104.1^{\circ}$ and $110.9^{\circ}$, corresponding to the (111), (200), (220), (311) and (222) Bragg's reflections that determine the face-centered-cubic ( $\mathrm{fcc}$ ) crystal structure of AgNPs. The broadening of the Bragg's peaks indicates the formation of Ag NPs. The XRD pattern thus shows that the

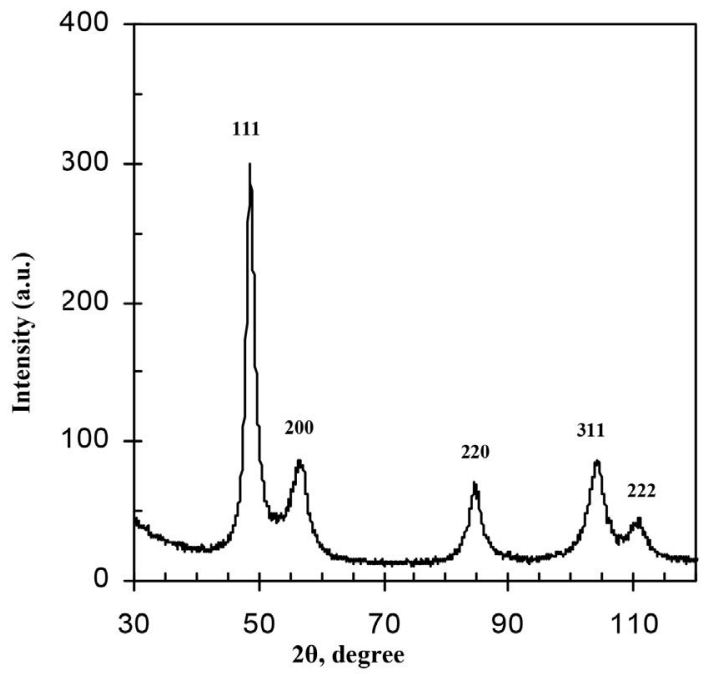

Fig. 1. XRD patterns of silver nanoparticles synthesized with PTHQ usage

Ag NPs formed by the reduction of $\mathrm{Ag}^{+}$ions by PTHQ polymer are of the crystalline nature. The average size of the Ag nanoparticles has been calculated from the XRD line width using the Debye-Scherrer equation ${ }^{23}$ and was found to be equal $20.8 \mathrm{~nm}$.

Transmission electron microscopy (TEM) study. TEM was used to determine the size and shape of the nanoparticles. The TEM images of the PTHQ, prepared 

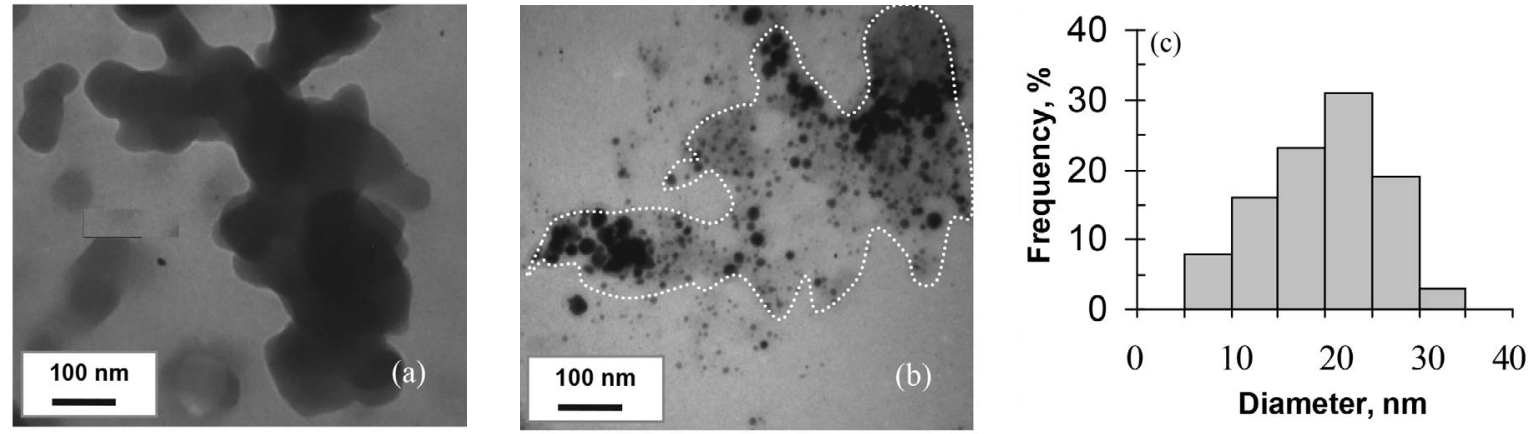

Fig. 2. The TEM images of PTHQ (a), AgNPs (b) and the corresponding size distribution histograms of AgNPs stabilized by PTHQ (c). The borders of the PTHQ globule are shown by the dotted line in part (b).

AgNPs are shown in the Fig. 2. TEM images show that they have spherical shape. A particle size distribution histogram determined from TEM is shown in Fig. 2c. The average AgNPs size is $19.8 \mathrm{~nm}$. The particle sizes calculated from the XRD pattern have been found to vary within $5 \%$ of those obtained from TEM studies. The main difference of these hydrosols from similar nanosystems received with the use of other reducers, in particular the humic substances ${ }^{15}$ is that the metal nanoparticles are fixed on the globule of the polymer.

Study of the silver nanoparticles formation by UV-Vis spectroscopy. The most popular method applied for the measurements of the kinetics of nanocluster formation in solution is UV-Visible spectroscopy since the sharp surface plasmon resonance band with maximum at 400 $\mathrm{nm}$ is a distinctive feature of the silver colloids. ${ }^{24,25}$ Evolution of the absorption spectrum of the silver colloidal solution during reduction of the $\mathrm{Ag}^{+}$ions by PTHQ at $30^{\circ} \mathrm{C}$ is shown in Figure $3 a$. For the early stages of clusters formation, the broad absorption band near $480 \mathrm{~nm}$ appeared which indicates the formation of small $\mathrm{Ag}$ particles on the surface of the large $\mathrm{Ag}_{2} \mathrm{O}$ particles. That position of this band absorption is the result in electronic interactions be- tween the two types of materials because $\mathrm{Ag}_{2} \mathrm{O}$ has semiconducting properties. Research by the authors ${ }^{26}$ has explained this fact by electron density transfer from the pure metal to the metal oxide nanoparticles when the small silver particles are formed on the surface of the n-type $\mathrm{Ag}_{2} \mathrm{O}$ semiconductor. At longer reaction times, the absorption band shifts continuously to shorter wavelengths. The increase of absorption maximum intensity over the time is connected with continuation of the $\mathrm{Ag}^{+}$ions reduction process and with the increase of the number of the colloidal particles. The final surface plasmon resonance band has been observed at $400 \mathrm{~nm}$ (Figure 3a).

To investigate the reaction kinetics of the AgNPs formation, the absorbance at $400 \mathrm{~nm}$ has been plotted against the reaction time (Figure $3 \mathrm{~b}$ ). The visible absorbance of the product can be observed immediately after the mixing of the reagents and rises rapidly at the beginning of the reaction. Then absorbance reaches a plateau, which indicates the reaction completion (Figure $3 b$ ).

Proposed mechanism of silver nanoparticles formation. Evidently, at the initial stage of the $\mathrm{Ag}^{+}$cations reaction with the $\mathrm{OH}^{-}$anions in the presence of PTHQ the formation of an $\mathrm{Ag}_{2} \mathrm{O}$ microphase occurs. However, the
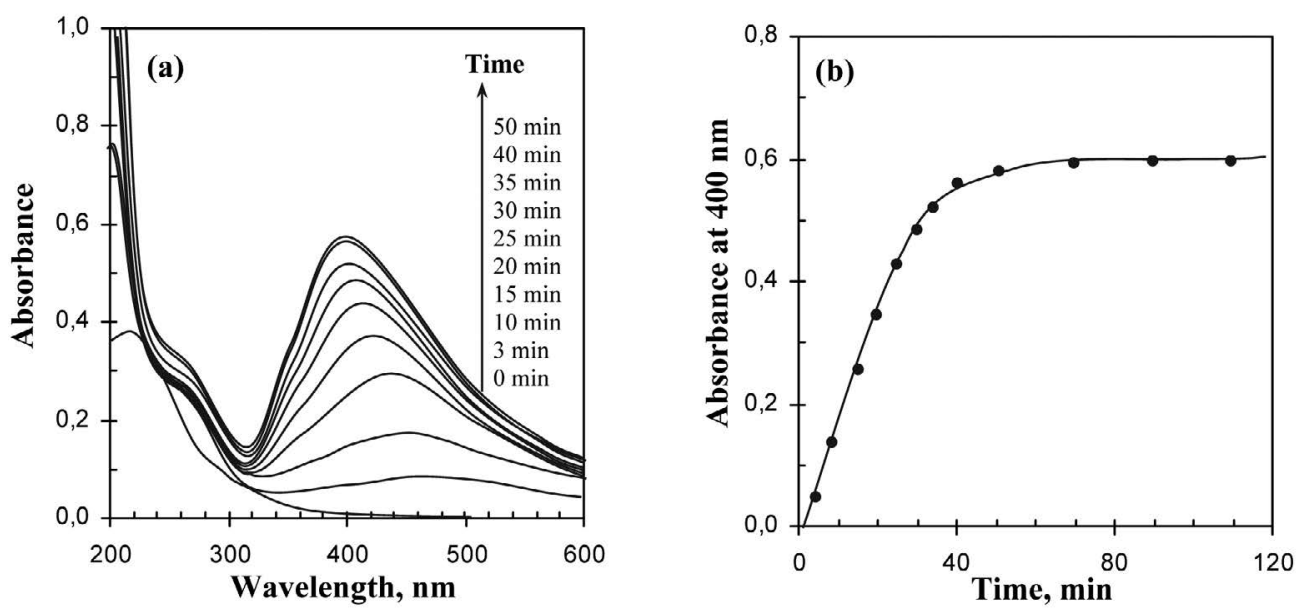

Fig. 3. The UV-Visible spectra of silver nanoparticles as a function of time (a); Absorbance at $400 \mathrm{~nm}$ versus time plot for the silver nanoparticles formation (b) 
detection of $\mathrm{Ag}_{2} \mathrm{O}$ microphase in similar systems by X-ray diffraction is extremely difficult, no mater how fast the separation of the precipitate from the solution is. ${ }^{27}$ Huang et al. ${ }^{26}$ have shown that it might be possible to capture some $\mathrm{Ag}_{2} \mathrm{O}$ if the reaction was performed at a very low temperature $\left(-45^{\circ} \mathrm{C}\right)$.

The polymer chemisorbed on the $\mathrm{Ag}_{2} \mathrm{O}$ particles in the alkaline environment has a negative charge due to ionization of the phenolic group, something that provides stabilization of nanoparticles. In the system " $\mathrm{Ag}_{2} \mathrm{O}$ - organic reducer" few simultaneous processes can take place. The first of them is a dissolution of $\mathrm{Ag}_{2} \mathrm{O}$ with the subsequent dissociation of $\mathrm{AgOH}$ :

$$
\begin{aligned}
& \mathrm{Ag}_{2} \mathrm{O}+\mathrm{H}_{2} \mathrm{O}=2 \mathrm{AgOH} \\
& \mathrm{AgOH} \Leftrightarrow \mathrm{Ag}^{+}+\mathrm{OH}^{-}
\end{aligned}
$$

The equilibrium within the $\mathrm{Ag}_{2} \mathrm{O}-\mathrm{H}_{2} \mathrm{O}$ system can be considered as a metallo-buffer for the $\mathrm{Ag}^{+}$ions, and where the concentration of the latter shows a hyperbolic function of the $\mathrm{OH}^{-}$ion concentration. Thus, in water suspension of the $\mathrm{Ag}_{2} \mathrm{O}$ species under intense stirring condition, the $\mathrm{Ag}^{+}$ ion concentration is expected to be constant and equal to $1.39 \cdot 10^{-4} \mathrm{M}$ (the solubility of $\mathrm{Ag}_{2} \mathrm{O}$ is $1.95 \cdot 10^{-8}$ ).

At the same time, the other important process of the NPs growth includes interaction of PTHQ with $\mathrm{Ag}^{+}$and
$\mathrm{OH}^{-}$ions, which results in the metal atom formation being aggregated into the nanoparticles. The major reducing groups in the structure of the PTHQ polymer are the phenolic groups, which are oxidized to the quinone structures. Thus, in situ-generated $\mathrm{Ag}_{2} \mathrm{O}$ nanocrystallites act as heterogeneous nucleation centers. The reduction of $\mathrm{Ag}^{+}$ions proceeds according to the following scheme:

The reduction reaction will proceed in the system until the whole $\mathrm{Ag}_{2} \mathrm{O}$ microphase is dissolved or the reductive possibilities of the organic reducer will be exhausted. However, during the synthesis the molar ratio "Ag': elementary link PTHQ" $(r)$ did not exceed 6. If $r>6$ a formation of a black deposit already in the course of the nanosystem synthesis was observed. Apparently, at excess of the ratio, the polymer will not have enough phenolic groups for delivery of a stabilizing charge to the complex particles $[\mathrm{Ag} @ \mathrm{PTOH}]^{x_{-}}$according to Eq. 4 (Scheme 1).

From this equation, it is clear, that the reductive ability of the aromatic core was practically exhausted, and that there is no possibility of formation of a sufficient amount of ionized hydroxyl groups for the maintenance of a negative charge of the complex. However, from the scheme 1 the possibility of a stable nanosystem formation at $r=8$ follows, but the real ratio $r$ is much lower because of the presence of the ditiocianhydroquinone bridges in the PTHQ structure.<smiles>CC(C)Sc1cc(O)ccc1O</smiles><smiles>CC(C)SC1=CC(=O)C=CC1=O</smiles>

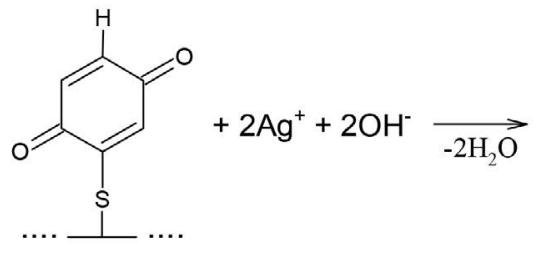<smiles>CC(C)SC1=CC(=O)C(O)=CC1=O</smiles><smiles>CC(C)SC1=CC(=O)C(O)=CC1=O</smiles><smiles>CC(C)SC1=CC(=O)C(O)=C(O)C1=O</smiles>

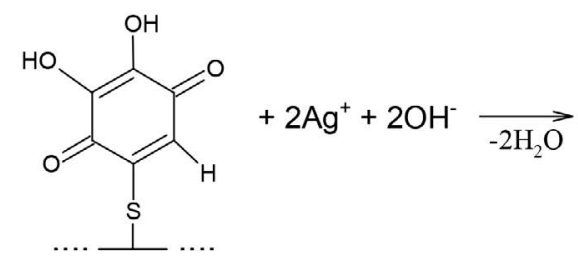<smiles>CC(C)Sc1c(O)c(=O)c(=O)c(=O)c1=O</smiles>

Scheme 1. Proposed mechanism for the reduction of $\mathrm{Ag}^{+}$ions by PTHQ in alkaline media 


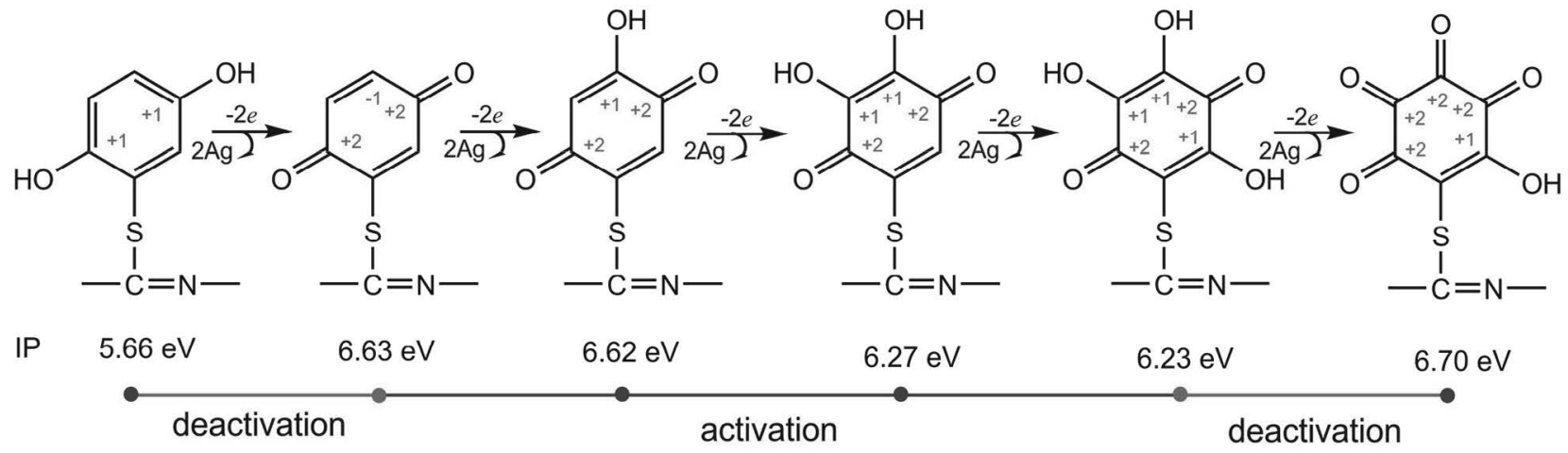

Scheme 2. The reductive ability of PTHQ active site upon the gradual rising of silver cluster

In order to explain how the reductive ability of PTHQ changes with the AgNPs growing we have performed the quantum-chemical estimations for ionization potentials of the PTHQ active site in different oxidation states. As can be seen from Scheme 2 the ionization potential of the PTHQ active site increases strongly (5.66 vs. $6.63 \mathrm{eV}$ ) right after the first stage when two hydroxyl groups transform into carbonyl groups. Actually, this stage provides the deactivation of PTHQ for the next reduction activity. However, assuming the possible next oxidation steps of the quinone ring in Scheme 1 we have found that the corresponding ionization potential (IP) decreases gradually with the appearance of $\mathrm{OH}$ groups $(6.63 \mathrm{eV}$ for quinone ring $v$. $6.23 \mathrm{eV}$ for trihydroxyquinone moiety), i.e. the reductive ability of PTHQ increases with the addition of new $\mathrm{OH}$ groups. We consider these stages as the activation of PTHQ for reductive activity. Finally, the oxidation of trihydroxyquinone ring into the tetra-carbonyl form provides a complete deactivation of PTHQ active site due to its final IP increase and the complete electronic exhaustion.

Concluding shortly, we should note that these computational findings additionally approve the proposed mechanism (scheme 1) for the reduction of $\mathrm{Ag}^{+}$ions by PTHQ in alkaline media. Moreover, the tendency for the IP changes upon PTHQ oxidation sequence is in a good agreement with the experimental kinetic measurements data for the silver cation reduction.

Potentiometric study of the kinetics and mechansim of the silver nanoparticles formation. For real-time control of the $\mathrm{Ag}^{+}$ion reduction process, we have used a potentiometric method, as ion-selective electrodes (ISE) responds continuously and instantaneously to the changes of the silver ion concentration. ${ }^{28,29}$ The potentiometric method for studying the chemical reaction kinetic is based on measurements and interpretation of the time dependence of the redox potential for the indicator electrode reversible to the particles participating in the studied reaction. A use of this dependence in the kinetic studies is only possible if the rate of the establishment of the electrode equilibrium is higher than the rate of introduction of all others equilibriums in the system with the potential-deter- mined particles. As the $\mathrm{Ag}^{+} / \mathrm{Ag}$ system is one of the most prompt redox systems we can use the potentiometric method in our studies. Since the signal output of the ISE corresponds to the logarithm of the concentration of the solute ions, such a direct potentiometric control of the depleted metal ions provides additional information on the nanoparticle formation, which is not accessible by other techniques. In our work, we have used a simple silver electrode instead of ISE since the studied system does not contain any perturbing ions. The silver electrode is particularly useful for gaining information about the kinetic processes at later stages of the nanoparticle growth, in which case the solute ions become dilute and the concentration changes are much more easily discerned compared to other methods. The potentiometric curves of $\mathrm{pAg}$ as a function of time for the process of the AgNPs formation using PTHQ at different temperatures are shown in Fig. 4. The figure indicates a three-step growth process ( $a b ; b c$ and $c d$ site).

Let us consider the correspondence of different regions on the potentiometric curve (Fig. 4) to the kinetic stages of the process proposed in Scheme 1. The decrease of the pAg curve ( $\boldsymbol{a} \boldsymbol{b}$ site) indicates the balance displace-

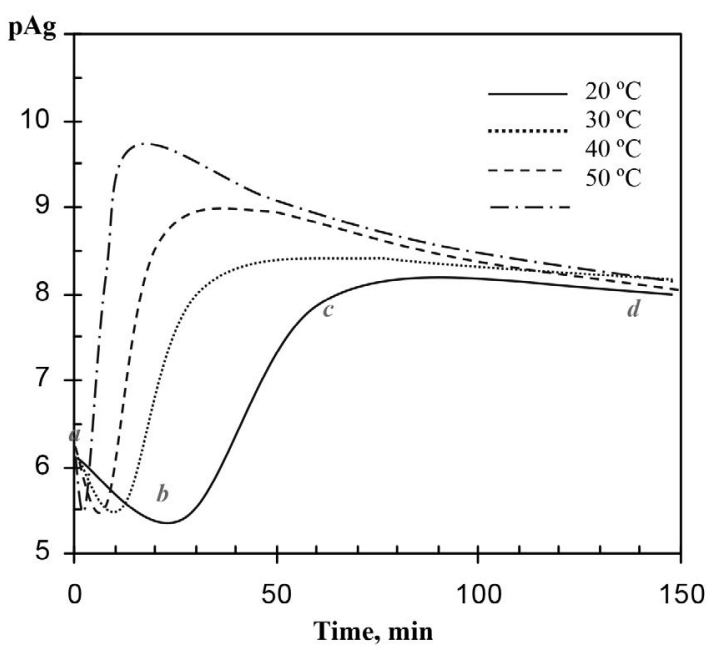

Fig. 4. The pAg potentiometric curves as a function of time for silver nanoparticles formation process at different temperatures 
ment in $\mathrm{Ag}_{2} \mathrm{O}$ dissociation as a result of a decrease in the concentration of the $\mathrm{OH}^{-}$ions which are also the reagents of the given reaction.

As the reaction of silver ion reduction occurs on the surface of the $\mathrm{Ag}_{2} \mathrm{O}$ particles (heterogeneous process), the rate of reaction does not depend on the $\mathrm{Ag}_{2} \mathrm{O}$ concentration in solution. Thus, this stage is described by a zero-order kinetics in respect to $\mathrm{Ag}_{2} \mathrm{O}$ and the rate constant $\left(k_{0}\right)$ of the AgNPs formation at the initial stage can be found from the equation: $k_{0}=d n\left(\mathrm{Ag}_{2} \mathrm{O}\right) / d t$, where $n\left(\mathrm{Ag}_{2} \mathrm{O}\right)$ - is an amount of the $\mathrm{Ag}_{2} \mathrm{O}$ microphase (mole); $t$ - time of the $\mathrm{Ag}_{2} \mathrm{O}$ microphase existence in the system (s); $k_{0}$ - zero-order rate constant $\left(\right.$ mole $\left.\cdot \mathrm{s}^{-1}\right)$.

At the point $\boldsymbol{b}$ of the pAg curve the whole $\mathrm{Ag}_{2} \mathrm{O}$ microphase is dissolved and begins the growth of $\mathrm{pAg}$ values according to the linear law that specifies the first order reaction with respect to $\mathrm{Ag}^{+}$-ion. The rate constant at this stage can be found from the following equation: $k_{1}=F / R T$

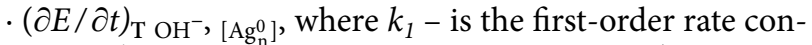
stant $\left(\mathrm{s}^{-1}\right), F$ - is the Faraday constant $\left(9.65 \cdot 10^{4}\right.$ coulomb/ mole); $R$ - the universal gas constant $\left(8.314 \mathrm{JK}^{-1} \mathrm{~mol}^{-1}\right), T$

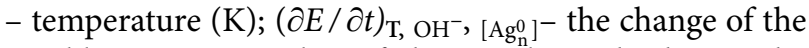
equilibrium potential $E$ of the Ag-electrode during the time $t$. The value of the derivative $(\partial E / \partial t)_{\mathrm{T}, \mathrm{OH}^{-},\left[\mathrm{Ag}_{\mathrm{n}}^{0}\right] \text { was }}$ determined from the measurements of the slopes of the linear parts of the pAg plots versus time (bc site, Fig. $5 \mathrm{~A}$ ), taking into account that $E=2.303 \cdot(R T / F) \cdot \Delta \mathrm{pAg}$.

At a point $c$ the pAg curve passes through a maximum. Some decrease of the pAg values ( $\boldsymbol{c d}$ site) corresponds to an increase in the concentration of the $\mathrm{Ag}^{+}$ions due to oxidation of the AgNPs by air oxygen ${ }^{30,31}$ according to the equation:

$$
4 \mathrm{Ag}^{0}+\mathrm{O}_{2}+4 \mathrm{H}^{+} \rightarrow 4 \mathrm{Ag}^{+}+2 \mathrm{H}_{2} \mathrm{O}
$$

The process described by Eq. (5) was controlled by $\mathrm{N}_{2}$ barbotation through the reaction solvent. In this case the pAg potentiometric curve after the point $c$ in Fig. 4 does not go down. This is because the AgNPs are quite small and very reactive (the surface/volume ratio is great) in comparison with the massive silver metal.

On the ground of potentiometric curves it is possible to make a conclusion that the formation mechanism of the AgNPs with the use of PTHQ is similar to those mechanisms which use the synthetic humic substances; ${ }^{30}$ in particular: 1) a fast formation of the $\mathrm{Ag}_{2} \mathrm{O}$ microphase in the system after mixing of reagents; 2 ) reduction of silver ions on the surface of the $\mathrm{Ag}_{2} \mathrm{O}$ particles according to the zero-order kinetics; 3 ) growth of AgNPs due to reduction of silver ions from solution on a surface of already generated

Table 1. Dependence of the rate constants at various temperatures for different stages of silver nanoparticles formation using PTHQ

\begin{tabular}{cccccccc}
\hline \multicolumn{2}{c}{$\begin{array}{c}\text { Initial stage } \\
\text { zero-order rate constants } \\
\mathbf{k}_{\mathbf{0}} \cdot \mathbf{1 0}^{\mathbf{3}}\left(\mathbf{m o l e} \cdot \mathbf{s}^{-1}\right)\end{array}$} & \multicolumn{5}{c}{$\begin{array}{c}\text { Later stage } \\
\text { first-order rate constants } \\
\boldsymbol{k}_{\mathbf{1}} \cdot \mathbf{1 0}^{\mathbf{3}}\left(\mathbf{s}^{-1}\right)\end{array}$} \\
\hline $293 \mathrm{~K}$ & $303 \mathrm{~K}$ & $313 \mathrm{~K}$ & $323 \mathrm{~K}$ & $293 \mathrm{~K}$ & $303 \mathrm{~K}$ & $313 \mathrm{~K}$ & $323 \mathrm{~K}$ \\
0.25 & 0.60 & 0.92 & 1.20 & 1.62 & 3.83 & 5.64 & 7.50 \\
\hline
\end{tabular}
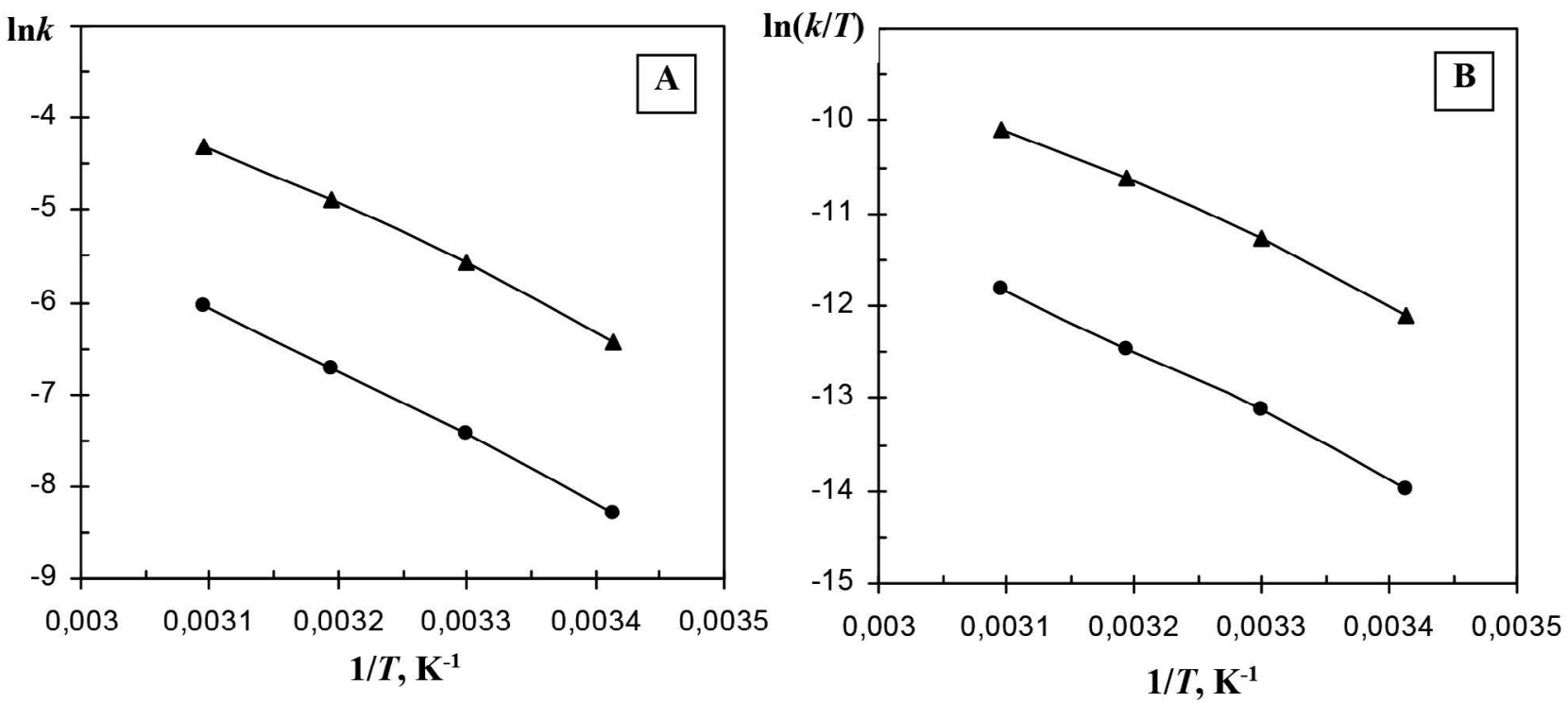

Fig. 5. The Arrhenius (A) and Eyring (B) plots of the silver nanoparticles formation for the initial $(\bullet)$ and later $(\mathbf{\Delta})$ stages using the PTHQ reagent 
nuclei of AgNPs according to the first order kinetics after the $\mathrm{Ag}_{2} \mathrm{O}$ microphase dissolution.

The temperature influence on the reaction rate was also studied. Calculated values of the zero-order rate constant $\left(k_{0}\right)$ for the initial stage of nanoparticles formation (before full dissolution of $\mathrm{Ag}_{2} \mathrm{O}$ ) and the first-order rate constants $\left(k_{1}\right)$ at the later stages of the nanoparticle growth for different temperature are presented in Table 1. It is possible to observe that the reaction rate increases with temperature. No extra yield is obtained at higher temperature. The data suggest that the process can easily be promoted by the thermal activation mechanism.

Since the reduction of $\mathrm{Ag}^{+}$ions occurs at the surface of $\mathrm{Ag}^{0}$ nuclei in the contact place of metal and silver oxide solid phases, the reaction rate does not depend on $\mathrm{Ag}_{2} \mathrm{O}$ concentration in the solvent. Thus, the reaction rate constant of the $\mathrm{Ag}_{2} \mathrm{O}$ depletion for the $\mathrm{Ag}$ NPs production at this initial stage is determined by the zero kinetic order according to equation $k_{0}=d n\left(\mathrm{Ag}_{2} \mathrm{O}\right) / d t$

Finally, from the Arrhenius Equation $\left(k=\mathrm{Ae}^{-\mathrm{Ea} / \mathrm{RT}}\right)$ and the Eyring Equation plots (Fig. 5), the activation parameters, e.g. the activation energy $\left(\mathrm{E}_{\mathrm{a}}\right)$, the enthalpy $\left(\mathrm{H}^{\#}\right)$ and entropy $\left(\mathrm{S}^{\#}\right)$ of activation, were calculated.

The estimated values of these parameters for different stage of silver nanoparticle formation with the use of PTHQ as reducing and stabilizing agent are presented in Table 2.

The $\mathrm{Ag}_{2} \mathrm{O}$ suspension is the source of the $\mathrm{Ag}^{+}$ions at the initial stage. The rise of $\mathrm{Ag}^{+}$ion concentration in Fig. 4 ( $\boldsymbol{a} \boldsymbol{b}$ site), being determined by the decrease in concentration of the $\mathrm{OH}^{-}$ions working also as reagents in the reaction of $\mathrm{Ag}^{+}$with PTHQ polymer, is an important prerequisite for the upcoming activation process. The latter includes reduction of the ions with the simultaneous growth of nanoparticles. The organic polymer is a reservoir of electrons for the reduction processes, which is rather complicated; the $\mathrm{Ag}^{+}$ ions at the first stage represent large rising concentration. The activation energy spent for electron transfer from PTHQ polymer (all averaged processes presented in Scheme 1) includes $\mathrm{C}-\mathrm{O}$ and $\mathrm{O}-\mathrm{H}$ bond cleavage with simultaneous ionization and subsequent electron attachment.

The similar processes occur at the later stage but in the limit of a decreased $\mathrm{Ag}^{+}$ion concentration; the reaction strongly depends on this concentration (first order reaction). That is why the activation energies are quite similar for both stages (Table 2). The small difference can be connected with the fact that electronic resources are exhausted at the late step of the process.

\section{Conclusions}

A facile approach for the synthesis of stable aqueous colloids of silver nanoparticles (AgNPs) is described in the present work using the polythiocyanatohydroquinone (PTHQ) polymer as a reducing and stabilizing reagent in water. The AgNPs were characterized by different techniques such as UV-vis spectroscopy, X-ray diffraction and transmission electron microscopy. The TEM experiments indicate that these nanoparticles are formed with spherical shapes. The X-ray diffraction pattern shows a high purity and face centered cubic structure of the AgNPs. On the basis of various observations a three-step mechanism is proposed for the reduction of the silver ions by PTHQ: 1) a fast formation of the $\mathrm{Ag}_{2} \mathrm{O}$ microphase in the system after mixing of reagents; 2 ) a reduction of the silver ions on the surface of the $\mathrm{Ag}_{2} \mathrm{O}$ particles according to the zero-order kinetics; 3 ) a growth of AgNPs due to reduction of silver ions from a solution on the surface of already generated nuclear of AgNPs according to the first order kinetics after the $\mathrm{Ag}_{2} \mathrm{O}$ microphase dissolution. The kinetic constants at various temperatures and for different stages were calculated and thermodynamic activation parameters were determined by variable temperature kinetic studies.

\section{Acknowledgements}

The quantum-chemical calculations were performed with computational resources provided by the High Performance Computing Center North (HPC2N) which is a Swedish national center for Scientific and Parallel Computing through the project "Multiphysics Modeling of Molecular Materials" SNIC 2016-34-43. This work was supported by the Ministry of Education and Science of Ukraine (Project No. 0117U003908).

The authors declare that they have no conflict of interest.

\section{References}

1. Yu. Krutyakov, A. A. Kudrinskiy, A. Yu. Olenin, G. V. Lisichkin, Russ. Chem. Rev., 2008, 77, 233-251.

DOI:10.1070/RC2008v077n03ABEH003751

2. A. Polman, H. A. Atwater, Mater. Today, 2005, 8, 56. DOI:10.1016/S1369-7021(04)00685-6

Table 2. Activation parameters for different stages of silver nanoparticles formation using PTHQ.

\begin{tabular}{|c|c|c|c|c|c|}
\hline & Initial stage & & & Later stage & \\
\hline $\begin{array}{l}\text { Activation energy } \\
\qquad E_{a}, \mathrm{~kJ}\end{array}$ & 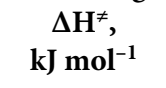 & $\begin{array}{c}\Delta \mathrm{S}^{\neq} \\
\mathrm{J} \mathrm{K}^{-1} \mathbf{m o l}^{-1}\end{array}$ & $\begin{array}{c}\text { Activation } \\
\text { energy } E_{a}, \mathrm{~kJ}\end{array}$ & $\begin{array}{c}\Delta \mathrm{H}^{\neq} \\
\mathrm{kJ} \mathrm{mol}^{-1}\end{array}$ & $\begin{array}{c}\Delta \mathrm{S}^{\neq}, \\
\mathrm{J} \mathrm{K}^{-1} \mathbf{m o l}^{-1}\end{array}$ \\
\hline 58.90 & 56.34 & -121.18 & 55.60 & 53.04 & -116.74 \\
\hline
\end{tabular}


3. K. Vasilev, V. R. Sah, R. V. Goreham, C. Ndi, R. D. Short, H. Griesser, J. Nanotechnol., 2010, 21, 5102-5107.

4. S. Prabhu, E. Poulose, Int. Nano Lett., 2012, 2, 1-10. DOI:10.1186/2228-5326-2-32

5. K. S. Lee, M. A. El-Sayed, J. Phys. Chem. B. 2006, 110, 19220 19225. DOI:10.1021/jp062536y

6. S. Kaviyaa, J. Santhanalakshmi, B. Viswanathan, J. Muthumary, K. Srinivasan, Spectrochim. Acta A, 2011, 79, 594-598. DOI:10.1016/j.saa.2011.03.040

7. R. F. Elsupikhe, K. Shameli, M. B. Ahmad, N. A. Ibrahim, N. Zainudin, Nanoscale Res. Lett., 2015, 10, 302.

DOI:10.1186/s11671-015-0916-1

8. J. Yang, H. Yin, J. Jia and Y. Wei, Langmuir, 2011, 27, 50475053. DOI:10.1021/la200013z

9. M. Harada, C. Kawasaki, K. Saijo, M. Demizu, Y. Kimura, J. Colloid Interface Sci., 2010, 343, 537-545.

DOI:10.1016/j.jcis.2009.11.066

10. M. Manoth, K. Manzoor, M.K. Patra, P. Pandey, S.R. Vadera, N. Kumar, Mater. Res. Bull., 2009, 44, 714-717.

DOI:10.1016/j.materresbull.2008.06.033

11. M. C. Rodriguez-Argüelles, C. Sieiro, R. Cao, L. Nasi, J. Colloid Interface Sci., 2011, 364, 80-84.

DOI:10.1016/j.jcis.2011.08.006

12. M. M. Kemp, A. Kumar, S. Mousa, T-J. Park, P. Ajayan, N. Kubotera, S. A. Mousa, R.J. Linhardt, Biomacromolecules, 2009, 10, 589-595. DOI:10.1021/bm801266t

13. V. A. Litvin, B. F. Minaev, G. V. Baryshnikov, J. Mol. Struct., 2015, 1086, 25-33. DOI:10.1016/j.molstruc.2014.12.091

14. L. Quaroni, G. Chumanov, J. Am. Chem. Soc., 1999, 121, 10642. DOI:10.1021/ja992088q

15. V. A. Litvin, B. F. Minaev, Mater. Chem. Phys., 2014, 144, 168-178. DOI:10.1016/j.matchemphys.2013.12.039

16. V. A. Litvin, R.L. Galagan, B. F. Minaev, Russ. J. Appl. Chem., 2012, 85, 296-302. DOI:10.1134/S1070427212020243

17. G. V. Baryshnikov, R. L. Galagan, L. P. Shepetun, V. A. Litvin, B. F. Minaev, J. Mol. Struct., 2015, 1096, 15-20.

DOI:10.1016/j.molstruc.2015.04.040

18. D. Becke, Phys. Rev. A, 1988, 38, 3098-3100.

DOI:10.1103/PhysRevA.38.3098

19. C. Lee, W. Yang, R.G. Parr, Phys. Rev. B, 1988, 37, 785-789.

DOI:10.1103/PhysRevB.37.785

20. M. M. Francl, W. J. Pietro, W. J. Hehre, J. S. Binkley, M. S.
Gordon, D. J. DeFrees, J. A. Pople, J. Chem. Phys., 1982, 77, 3654-3665. DOI:10.1063/1.444267

21. S. Miertus, E. E. Scrocco, Tomasi, J. Chem. Phys., 1981, 55, 117-129.

22. M. J. Frisch, G. W. Trucks, H. B. Schlegel, G. E. Scuseria, M. A. Robb, J. R. Cheeseman, G. Scalmani, V. Barone, G. A. Petersson, H. Nakatsuji, X. Li, M. Caricato, A. V. Marenich, J. Bloino, B. G. Janesko, R. Gomperts, B. Mennucci, H.P. Hratchian, J. V. Ortiz, A. F. Izmaylov, J. L. Sonnenberg, D. Williams-Young, F. Ding, F. Lipparini, F. Egidi, J. Goings, B. Peng, A. Petrone, T. Henderson, D. Ranasinghe, V. G. Zakrzewski, J. Gao, N. Rega, G. Zheng, W. Liang, M. Hada, M. Ehara, K. Toyota, R. Fukuda, J. Hasegawa, M. Ishida, T. Nakajima, Y. Honda, O. Kitao, H. Nakai, T. Vreven, K. Throssell, J. A. Montgomery, Jr., J. E. Peralta, F. Ogliaro, M. J. Bearpark, J. J. Heyd, E. N. Brothers, K. N. Kudin, V. N. Staroverov, T. A. Keith, R. Kobayashi, J. Normand, K. Raghavachari, A. P. Rendell, J. C. Burant, S. S. Iyengar, J. Tomasi, M. Cossi, J. M. Millam, M. Klene, C. Adamo, R. Cammi, J. W. Ochterski, R. L. Martin, K. Morokuma, O. Farkas, J. B. Foresman, D. J. Fox, Gaussian, Inc., Wallingford CT, 2016, Gaussian 16, Revision A.03.

23. C. Suryanarayana, M. Grantnorton X-Ray Diffraction: A Practical Approach, Plenum Publishing Corporation, New York, 1998. DOI:10.1007/978-1-4899-0148-4

24. V. K. Vidhu, S. A. Aromal, D. Philip, Spectrochim. Acta A, 2011, 83, 392- 397. DOI:10.1016/j.saa.2011.08.051

25. V. A. Litvin, B. F., Minaev, Spectrochim. Acta A, 2013, 108, 115-122. DOI:10.1016/j.saa.2013.01.049

26. Z-Y. Huang, G. Mills, B. Hajek, J. Phys. Chem., 1993, 97, 11542-11550. DOI:10.1021/j100146a031

27. K.-S. Chou, Yu-C. Lu, H.-H. Lee, Mater. Chem. Phys., 2005, 94, 429-433. DOI:10.1016/j.matchemphys.2005.05.029

28. T. C. Prathna, N. Chandrasekaran, A. M. Raichur, A. Mukherjee, Colloids Surf. A, 2011, 377, 212-216.

DOI:10.1016/j.colsurfa.2010.12.047

29. K. Y. Chumbimuni-Torres, E. Bakker, J. Wang, Electroch. Commun., 2009, 11, 1964-1967.

DOI:10.1016/j.elecom.2009.08.029

30. V. A. Litvin, R. L. Galagan, B. F. Minaev, Colloids Surf. A, 2012, 414, 234-243. DOI:10.1016/j.colsurfa.2012.08.036

31. J. Liu, R. H. Hurt, Environ. Sci. Technol., 2010, 44, 2169-2175. DOI:10.1016/j.colsurfa.2012.08.036

\section{Povzetek}

Motivirani z dokazi, da imajo nanodelci srebra številne tehnološke aplikacije, smo v tem delu raziskali uporabo politiocianatohidrokinona kot novega učinkovitega redukcijskega in stabilizacijskega reagenta za pripravo takšnih nanodelcev. Nanodelce srebra smo karakterizirali z UV-Vis spektroskopijo, rentgensko praškovno difrakcijo in presevno elektronsko mikroskopijo (TEM). Predstavljene so tudi potenciometrične in spektrofotometrične kinetične meritve rasti nanodelcev srebra. Termodinamične aktivacijske parametre za tvorbo nanodelcev srebra smo določili iz reakcijskih kinetičnih študij pri različnih temperaturah. Predlagali smo mehanizem za nastanek nanodelcev srebra. Velikost (20-40 nm) in sferična porazdelitev nanodelcev skupaj z visoko stabilnostjo koloidov nam dajeta trdno osnovo za morebitno uporabo polimera kot redukcijskega in stabilizacijskega regenta za pripravo in shranjevanje kovinskih nanodelcev. 